JSRM Code: 012020200010

\title{
New Trends in Heart Regeneration: A Review
}

\author{
Kochegarov $\mathrm{A}^{1}$, Lemanski $\mathrm{LF}^{1}$
}

\begin{abstract}
In this review, we focus on new approaches that could lead to the regeneration of heart muscle and the restoration of cardiac muscle function derived from newly-formed cardiomyocytes. Various strategies for the production of cardiomyocytes from embryonic stem cells, induced pluripotent stem cells, adult bone marrow stem cells and cardiac spheres from human heart biopsies are described. Pathological conditions which lead to atherosclerosis and coronary artery disease often are followed by myocardial infarction causing myocardial cell death. After cell death, there is very little self-regeneration of the cardiac muscle tissue, which is replaced by non-contractile connective tissue, thus weakening the ability of the heart muscle to contract fully and leading to heart failure. A number of experimental research approaches to stimulate heart muscle regeneration with the hope of regaining normal or near normal heart function in the damaged heart muscle have been attempted. Some of these very interesting studies have used a variety of stem cell types in combination with potential cardiogenic differentiation factors in an attempt to promote differentiation of new cardiac muscle for possible future use in the clinical treatment of patients who have suffered heart muscle damage from acute myocardial infarctions or related cardiovascular diseases. Although progress has been made in recent years relative to promoting the differentiation of cardiac muscle tissue from non-muscle cells, much work remains to be done for this technology to be used routinely in translational clinical medicine to treat patients with damaged heart muscle tissue and return such individuals to pre-heart-attack activity levels.
\end{abstract}

Key Words: Cardiac muscle regeneration, Embryonic stem cells, MicroRNAs, Adult stem cells, Mesenchymal stem cells, Induced pluripotent stem cells

\section{Introduction}

Atherosclerosis is a pathological condition resulting in the narrowing of blood vessels due to an accumulation of atherosclerotic plaques between the smooth muscle and endothelial layer leading to acute myocardial infarction with major damage to the cardiac muscle and even death to the individual. These plaques consist of lipids, calcium deposits, cellular debris and so-called foam cells. Molecular and cellular mechanisms for the origin(s) of atherosclerosis are not well understood. LDL (Low-density lipoprotein) accumulation in blood vessels that can be associated with age-related diseases such as diabetes are thought to be a primary step in the origin of atherosclerosis.

Currently, many researchers favor an inflammatory hypothesis in which LDL accumulation and its oxidation triggers an inflammatory response recruiting monocytes to the area and converting these cells into macrophages ${ }^{[1.2]}$. Macrophages engulf oxidized LDL and become foam cells, containing large droplets of lipid (lipid-loaded macrophages) that resemble foam in appearance in the atherosclerotic plaques ${ }^{[3]}$. When these lipid loaded macrophages die, they release their contents into the spaces between the vascular endothelium and smooth muscle layer creating a lipid core ${ }^{[3]}$. The other cells deposit fibers along the internal endothelial lining of blood vessels. Blood platelets can attach to the atherosclerotic plaques creating a blood clot that blocks or severely reduces the blood supply to, for example, the heart muscle and without blood, the myocardium is deprived of oxygen causing damage or death to the cardiac cells. Restoring blood flow to the heart after a myocardial infarction (MI) may cause even further damage of the muscle due to oxidative stress, known as reperfusion injury. Once the heart muscle has been damaged, very little repair or regeneration takes place to form functional new cardiac muscle.

Biomedical scientists and physicians have been working for more than 50 years to find ways to repair the heart muscle following a heart attack. Although a number of medications and procedures have been developed to provide significant improvements in heart function, none to date have provided a means to actually regenerate the damaged cardiac muscle and return the patients to pre-heart-attack activity levels. A major problem in heart regeneration after a myocardial infarction is that cardiomyocytes die and are replaced by non-contracting fibrous scar tissue rather than new cardiac muscle cells. This supports function of the damaged heart temporarily, but in the long term, it weakens the organ's ability to contract normally and increases the risk of a further heart attack. This is the major reason why myocardial infarctions are a leading killer around the world. Currently, the only option for a severely failing heart is organ transplantation and recently-developed heart-assist devices. Since the early 2000s, scientists have been trying to use pluripotent stem cells to grow new muscle in damaged hearts. Stem cells can produce multiple cell lineages in the body; the hope is that they will be able to generate new cardiomyocytes. However, earlier enthusiasm for using stem cell therapy to accomplish heart regeneration has declined because, to date, stem cells that show reliable cardiac lineage markers

Author Names in full: Andrei Kochegarov ${ }^{1}$, Larry F Lemanski ${ }^{1}$

${ }^{1}$ Department of Biological and Environmental Sciences, Texas A\&M University-Commerce, Commerce, Texas, USA 
have not met with major success in clinical trials using stem cell therapy. In spite of the clinical difficulties, multiple approaches and strategies continue to be investigated to regenerate injured heart tissue. These basic science approaches include studies on small molecules, microRNA treatment and stem cell differentiation in laboratory settings (summarized with reference citations in Table 1).

\section{Cardiomyocyte proliferation}

A significant obstacle for self-regeneration of damaged heart tissue is the inability of adult cardiomyocytes to proliferate. In mammals, cardiomyocytes decrease their ability to proliferate during late embryonic development and almost completely lose this proliferation ability a few days after birth. The other obstacle for cardiomyocyte proliferation is the lack of fusion of cardiomyocytes in a functional (but not anatomical) syncytium. The use of tissue scaffolds and tissue engineering may be useful in a functional and formal structure ${ }^{[4-7]}$. Originally, therapy with stem cells involved the simple injection of derived cardiomyocytes into the site of injury. Although this approach has shown promise in some experiments, many researchers noted some drawbacks such as low cellular retention and low engraftment rate of injected cells. To overcome these problems alternate approaches were developed, such as construction of biomimetic scaffolds using synthetic and natural materials and decellularized tissue scaffolds in the site of injury. These scaffolds provide places for the attachment and mechanical support of differentiated cardiomyocytes. The permanent scaffolds should be designed to meet many requirements including integration with cells inside the heart, electrical conduction, diffusion of oxygen and nutrients, and should stimulate cardiac differentiation and not cause an immune reaction. Biodegradable scaffolds are presumed to degrade over time, but are replaced with cardiomyocytes and extracellular matrix. One of the most advanced and promising approaches is to inject, together with cells, self-assembling peptide nanofibers, which rapidly selfassemble into a 3D nanofibril net on which the cells can grow ${ }^{[8]}$.

In the mid-gestation prenatal developmental period, the labeling index of new DNA synthesis was found to be $33 \%$ in 12 day in utero embryos; however, at birth, DNA synthesis in neonatal mice was estimated to be $2 \%$, and at 4-6 days postnatally, the DNA synthesis had increased to $10 \%{ }^{[9]}$. This increase takes place without cytokinesis, causing binucleation, multinucleation and polyploidisation of cardiac myocytes, without increases in cell numbers. During normal mouse heart development, cardiomyocyte proliferation virtually stops by post-natal day 7 , coinciding with a significant reduction of heart muscle differentiation. DNA synthesis in adult mouse heart, normal or injured, has been found to be extremely low at $0.0005 \%$ of the cells ${ }^{[10]}$.

In the human heart, apparently related to levels of development and aging, cardiomyocyte turnover is higher at age 10 (2\% per year), decreases by age 25 ( $1 \%$ per year) and further decreases at age 75 $(0.45 \% \text { per year })^{[11]}$. The source of new cardiomyocytes in humans is still not known. One hypothesis suggests that adult cardiomyocytes or a subpopulation of them, are able to proliferate at a very low rate. Recent animal studies conclude that cardiac stem cells contribute little to the proliferation of cardiomyocytes in adult mammals ${ }^{[12]}$. Alternatively, it has been proposed that cardiac progenitor cells or cardiac adult stem cells exist and proliferate in mature mammalian hearts ${ }^{[13,14]}$. This hypothesis is supported by localizing and isolating cardiac stem-cell-like progenitor cells in mammalian heart tissue ${ }^{[15]}$. However, the natural rate of cardiomyocyte proliferation is not adequate to replenish myocardial cell loss after myocardial infarction. There are published studies that suggest several potentially promising ways to stimulate heart regeneration as listed below in Table 1:

Table 1 Approaches to stimulate heart regeneration

\begin{tabular}{|c|c|c|}
\hline $\begin{array}{l}\text { Approaches to stimulate cardiomyocyte } \\
\text { proliferation/differentiation }\end{array}$ & Results & References \\
\hline $\begin{array}{l}\text { Delivery of Follistatin-Like-Protein } 1 \\
\text { (FSTL1) to the infarcted heart using a } \\
\text { collagen patch }\end{array}$ & $\begin{array}{l}\text { Activated cardiomyocyte proliferation in } \\
\text { border zone resulting in regeneration of } \\
\text { injured heart }\end{array}$ & Wei et al., 2015 $5^{[16]}$ \\
\hline $\begin{array}{l}\text { Multiple human micro RNA: miRNAs: miR- } \\
\text { 1825, miR-199a, miR-99a, miR-548c, miR- } \\
\text { 23b and others }\end{array}$ & $\begin{array}{l}\text { Cardiomyocyte proliferation in vitro is } \\
\text { promoted by adding these microRNAs }\end{array}$ & Pandey et al., 2015 $5^{[18]}$ \\
\hline miRNA-204 & $\begin{array}{l}\text { Cardiomyocyte proliferation in vitro and in } \\
\text { vivo is enhanced }\end{array}$ & Liang et al., 2015 ${ }^{[19]}$ \\
\hline miR-410 and miR-495 & $\begin{array}{l}\text { Expression of miR-410 and miR-495 } \\
\text { stimulates cardiomyocyte DNA synthesis and } \\
\text { cell division of cardiomyocytes }\end{array}$ & Clark et al., 2015 \\
\hline ESC-derived exosomes & $\begin{array}{l}\text { Stimulates and activates repair mechanisms of } \\
\text { heart tissue after myocardial infarction in vivo }\end{array}$ & $\begin{array}{l}\text { Kishore, et al., 2016 } \\
\text { Khan et al., 2015 } \\
\end{array}$ \\
\hline Induction of active ErbB2 (receptor of NRG1) & $\begin{array}{l}\text { Promotes cardiac muscle cell division and } \\
\text { dedifferentiation in vivo }\end{array}$ & D‘Uva et al., 2015 $5^{[28]}$ \\
\hline
\end{tabular}

Stimulates cardiac regeneration by

Neuregulin-1 cardiomyocyte protection $(38 \%)$ and Polizzotti et al., 2015 [29] proliferation $(62 \%)$ in vivo in both mouse and human

Acidic fibroblast growth factor (FGF1) and neuregulin-1 (NRG1)

Use of RNAs in tissue cultured cells

Use of tissue scaffolds and tissue engineering strategies
Stimulates cardiac regeneration and cardiomyocyte proliferation in a rat myocardial infarction model

Non-muscle stem cells express cardiac specific troponin-T and show cardiomyocyte morphologies in culture
Formiga et al., 2014 ${ }^{[30]}$

Kochegarov et al., 2015 $5^{[55,56]}$
Provide structural matrix scaffolds on which new cardiac cells can grow when stimulated by growth factors for cardiomyocytes
Boffito et al., 2014 ${ }^{[4]}$

Tallawi et al., $2015^{[5]}$

Wang et al., 2013 ${ }^{[6]}$

Alrefai et al., $2015^{[7]}$

Davis et al., 2005 ${ }^{[8]}$ 
Follistatin-Like-Protein 1 (FSTL1) is an epicardium-secreted factor that appears to have a cardioprotective role by activation of vascular remodeling and proliferation of cardiomyocytes. FSTL1 is a glycoprotein from the follistatin family that often accumulates in heart muscle cells, vascular cells, and fibroblasts; its expression is activated after ischemic and infarction injuries. In previous research, it was shown that FSTL1 increases cardiomyocyte survival and angiogenesis in infarcted areas of the heart. Recent research by Wei et al. ${ }^{[16]}$ suggests that FSTL1 also stimulates cardiomyocyte proliferation ${ }^{[16]}$. In fact, in a series of experiments, FSTL1 protein was delivered using collagen patches loaded with FSTL1 as depicted in Figure 1. Application of patches loaded with the FSTL1 protein to the heart after myocardial infarction, significantly improved the survival of myocytes, attenuated fibrosis, increased the number of vessels in injured areas and stimulated cardiomyocyte proliferation in the border zone of the heart infarct. Proliferating cardiomyocytes were present mostly in the border zone, presumably because this zone has a continuous blood supply. In the definitive infarcted area, proliferating cardiomyocytes were much reduced ${ }^{[16]}$. Thus, epicardial delivery of FSTL1 through collagen patch delivery significantly improved heart regeneration by activating cardiomyocyte proliferation.

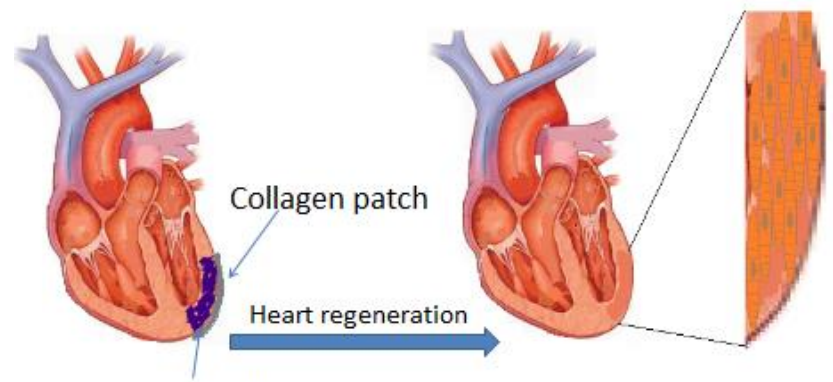

Infarcted area

Figure 1. Diagramatic representation of delivery of Follistatin-Like-Protein 1 (FSTL1) to the infarcted area of a heart using a collagen patch.

Multiple microRNAs have been reported as being promising for promoting cardiac muscle regeneration by causing a stimulation of cardiomyocyte proliferation and differentiation. MicroRNAs play a significant role in the regulation of gene expression as well as in modifications at the post-transcriptional level. Experiments by Chen et al., ${ }^{[17]}$ show that transgenic overexpression of miR-17-92 in cardiomyocytes causes cardiomyocyte proliferation in adult hearts. Notably, combinations of miR-590, miR-199a, and the miR-17-92 induce mouse cardiomyocyte proliferation both in vitro and in vivo ${ }^{[17]}$. Moreover, overexpression of miR-17-92 in adult cardiomyocytes protects cardiac muscle tissue from injuries induced by infarction. To date, the most potent microRNAs that appear to induce cardiomyocyte proliferation in tissue culture experiments have been human miR1825, miR-199a-3p, miR-99a-5p, miR-548c-3p and miR-23b-3 $p^{[18]}$. MiRNA-204 overexpression stimulates cardiomyocyte proliferation in neonatal and adult rat cardiomyocytes in vitro ${ }^{[18]}$. In these experiments, miRNA-204 seems to upregulate cyclins through inhibition of the JARID2 signaling system (Cyclin A, Cyclin B, Cyclin D2, Cyclin E, CDC2) and appears to be responsible for progression of the cell cycle and proliferation ${ }^{[19]}$. Another very promising approach was described recently for the delivery of neuregulin into infarcted heart tissue using biodegradable microparticles made of polylactic glycolic acid and polyethylene glycol $^{[20]}$. Using this approach, microparticles loaded with neuregulin degrade up to 12 weeks, slowly releasing the active compound. This material also was shown to be resistant to phagocytosis by macrophages and other immune cells which is important for targeted delivery. Technically, these microparticles can be applied to infarcted hearts as a spray with biodegradable glue.
In other studies, overexpression of miR-410 and miR-495 results in robust neonatal cardiomyocyte proliferation ${ }^{[21]}$. The miRNAs together with other regulating cardiogenic factors appear to be synthesized by endothelial cells, cardiac stem cells, fibroblasts and other cells. Moreover, these factors are shuttled via extracellular vesicles (exosomes) into cardiomyocytes where they regulate cardiogenesis during development and regeneration ${ }^{[22]}$. ESC-derived exosomes provide novel delivery tools to shuttle factors from ES cells to stimulate and activate repair mechanisms after myocardial infarction ${ }^{[23]}$. In another recent study, mouse ESC-derived exosomes enhanced a cardiac proliferative response, vascular angiogenesis, cardiomyocyte survival, and reduced fibrotic scar formation after myocardial infarction. Studies of exosome active factors revealed a significant presence of miR290-295 and miR-294 ${ }^{[24]}$. Small organic molecules also can be used to activate cardiomyocyte proliferation. In previous experiments, the administration of 2 , 3, 5, 4'-tetrahydroxystilbene-2-O- $\beta$-d-glucoside (THSG) have shown protection of in vivo heart muscle tissue from ischemic injuries of rat cardiac stem cells (CSC) in culture and an increased expression of cardiac specific markers for stem cells in vitro ${ }^{[25]}$.

Neuregulin-1 (NRG1) growth factor induces the growth and differentiation of many types of cells including epithelial, glial, neuronal, and skeletal muscle cells. NRG1 also was found to be an important factor in heart development, because mice with mutations in NRG1 or with loss of two receptors for this factor (ErbB2 and ErbB4), die from a lack of differentiation of normal heart muscle ${ }^{[26]}$. Neuregulin-1 (NRG1) may induce heart regeneration through the proliferation and survival of stem cells as summarized in Figure 2. Very recently, Yutzey et al., have suggested that Neuregulin-1 administration may promote cardiac regeneration ${ }^{[27]}$. Activation of a signaling mechanism by Neuregulin-1 through its receptor ErbB2 has been shown to induce proliferation of quiescent cardiomyocytes and trigger cardiomyocyte proliferation after myocardial infarction ${ }^{[28-}$ ${ }^{30]}$. Based on other studies, the Hyppo/Yap pathway is believed to participate in regulating organ size during development, although the mechanism(s) controlling organ size in adults is not known ${ }^{[31]}$. Recently, approaches to inhibit the Hyppo pathway by microRNAs have been proposed as a stimulant of cardiac proliferation ${ }^{[32]}$.

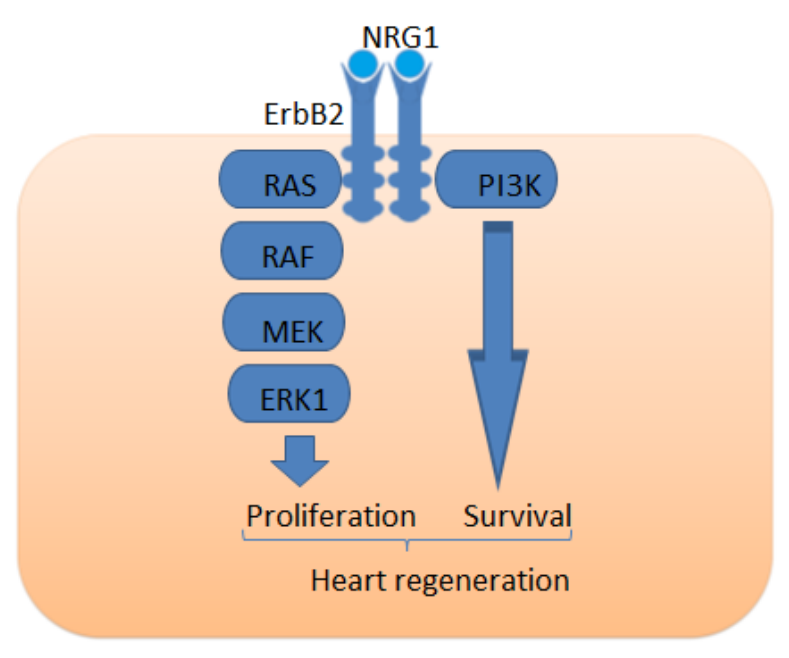

Figure 2. Neuregulin-1 (NRG1) appears to induce heart regeneration through the activation of proliferation and survival of stem cells. 


\section{Cell-Based Therapy for Heart Failure}

\subsection{Bone marrow}

Bone marrow has been found to have various cell types, including three types of stem cells: 1. hematopoietic stem cells (HSC); 2. mesenchymal stem cells (MSC); and 3. endothelial progenitor cells (EPCs). The stem cells from bone marrow are often termed bone marrow mononuclear cells (BM-MNC). Recent studies suggest that unfractionated BM-MNCs consist of a mixed population of hematopoietic cells, including monocytes and lymphocytes, hematopoietic cells and mesenchymal cells. Studies in animal models of the ischemic myocardium indicate that mononuclear bone marrow stem cells implanted into the heart improve angiogenesis, left ventricular function and cardiac muscle perfusion ${ }^{[33]}$. Currently, autologous bone marrow stem cell transplants are considered safe to use as a treatment to improve post-myocardial infarction hearts in humans ${ }^{[34]}$. From 2002 to 2010, the first stem-cell-based clinical trials for AMI (acute myocardial infarction) with transplanted heterogeneous adult BM-MNC showed a significant decrease in infarction size and an overall improved myocardial oxygen uptake resulting in a statistically significant $15 \%$ reduction of inpatient mortality ${ }^{[35]}$.

\subsection{Mesenchymal stem cells (MSC)}

Mesenchymal stem cells obtained from bone marrow are multipotent stem cells with fibroblast-like morphologies. Mesenchymal stem cells are separated from other bone-marrow cells based on their adhesive properties. Mesenchymal stem cells adhere to plastic tissue culture plates within 24 to 48 hours, while red blood cells and hematopoetic progenitor cells (HCS) from bone marrow do not; thus, all cells that attach to the tissue culture dishes during this time, have been reported by Tondreau et al. ${ }^{[36]}$ to be pure MSC.

MSC readily differentiate into osteoblasts and chondrocytes as well as adipocytes, skeletal muscle myocytes/myotubes and pancreatic islet cells. The differentiation of MSC into cardiomyocytes also has been known for a long time and recent experiments confirm that these cells express cardiac specific markers for cardiomyocytes. Moreover, grafted MSC-derived cardiomyocyes have been observed at the site of

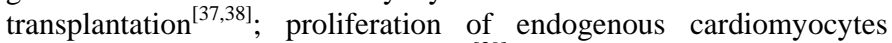
were noted after MSC treatment ${ }^{[39]}$. In vivo studies in other laboratories did not observe the engraftment of MSCs in murine infarcted hearts several weeks after acute $\mathrm{MI}^{[40]}$, and survival of the engrafted MSC was only about $2 \%$, with no evidence of cardiomyocyte differentiation in these cells ${ }^{[41]}$. Currently, most MSC described for in vivo studies report that the engrafted MSC die within two weeks of transplantation with little or no direct cardiac differentiation ${ }^{[41,42]}$. These observations have led to the idea that MSC transplantation into an infarcted heart may promote heart regeneration without incorporation of the MSC into the myocardium; rather paracrine factors (cytokines and growth factors) stimulate cardiomyocyte proliferation and neovascularization of the infarcted areas resulting in myocardial regeneration ${ }^{[43]}$. Cardiosphere-derived cells described in Section 2.3 may use a similar mechanism to MSC as summarized in Figure 3.

The first clinical trials of MSC were completed in 1995 when MSC were injected into patients' hearts to test the safety of the treatment. Since then, numerous experiments have been conducted which show a statistically significant improvement of $7 \%$ in myocardial regeneration and cardiac function in animal models after human MSC treatment ${ }^{[44]}$. Interestingly, it was shown that treatment with MSC can retard natural heart senescence and increase the life span in rodents by $22 \%{ }^{[45,46]}$. Although initially MSC were derived from bone marrow, more recently it has been found that MSC reside in and can be isolated from multiple adult tissues in the body such as dental pulp, umbilical cord blood, uterus, adipose tissue, peripheral blood, fallopian tubes, fetal liver, lung, etc. Thus, there are potentially numerous options for retrieving immune-compatible MSC from the body of a prospective patient for potential use in the treatment of heart failure/myocardial damage in that same patient.

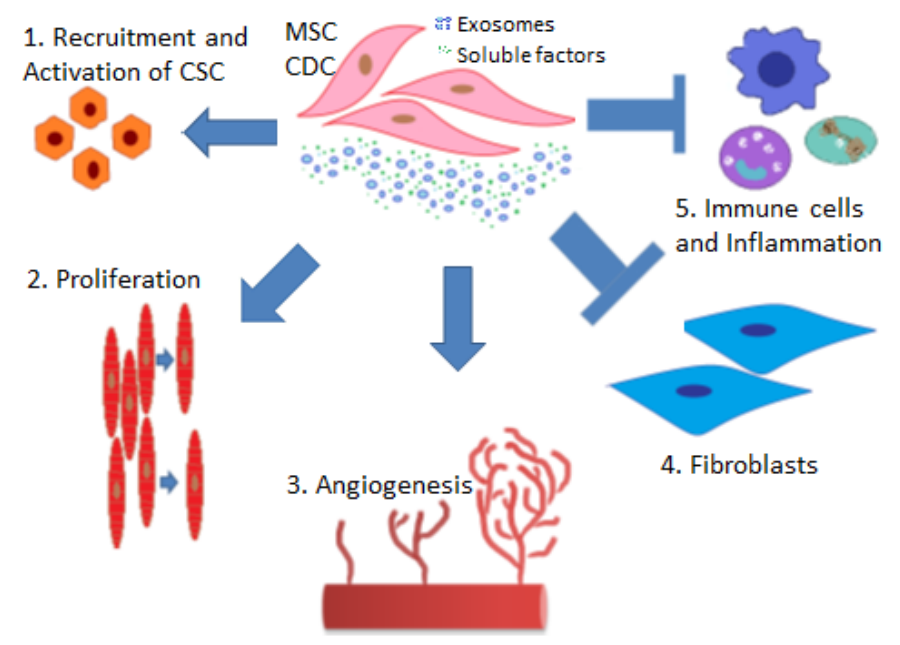

Figure 3. A model for a possible paracrine mechanism of how MSC (mesenchymal stem cells) and $C D C$ (cardiosphere-derived cells) promote heart regeneration via the secretion of exosomes (extracellular vesicles) and soluble factors by: 1. Recruitment and activation of cardiac stem cells (CSC), 2. Proliferation of cardiomyocytes in situ, 3. Angiogenesis and neovascularization, 4. Inhibition of fibrosis. 5. Inhibition of inflammation.

\subsection{Cardiosphere-Derived Cells (CDC)}

Cardiosphere-derived cells (CDC) as described here are those cells isolated from myocardial biopsy specimens of patients undergoing heart surgery. The heart fragments from these biopsies are cultured on fibronectin-coated Petri plates. After a few days in culture, the biopsied heart cells form into a monolayer over which smaller, rounded cells migrate. These small rounded cells appear to be of cardiogenic lineages and can be retrieved by enzymatic treatment followed by replating on poly-d-lysine-coated culture dishes using cardiac growth medium. The cells that remain adherent to the poly-dlysine-coated dishes after several days in culture are discarded, while the free floating "cardiospheres" are placed on fibronectin-coated culture dishes and grown into a monolayer ${ }^{[46,47]}$. Experiments performed by Marban's group demonstrated that cardiospheres and CDC express antigenic properties of stem cells, as well as cardiac contractile proteins and proteins related to cardiac electrophysiology ${ }^{[48]}$. Cardiac-derived cells injected into the myocardial infarct border zones appear to integrate into the heart wall and end up in the infarct zone. At three weeks post-injection, the healthy living myocardium in the infarct zone is significantly larger in the CDC-treated hearts ${ }^{[48]}$. To date, cell therapy with CDC has proven to be effective in repairing damaged human myocardial tissue. At this point, however, the source of the new heart muscle tissue per se and the mechanisms underlying its formation remain unknown. These new cardiomyocytes may have come from residual adult cardiac stem cells that were already present in the recipient heart muscle tissue and stimulated to form from the effects of paracrine factors resulting from the presence of the CDC (Figure 3). Scientists propose that CDC may localize to the area of the infarct and release factors which stimulate the heart to repair itself, ultimately reducing infarction size and fibrotic scar tissue and promoting growth of the heart muscle. After several weeks, the CDC clear from the heart without apparent side effects. Many investigators now think that these cells, as with bone marrow-derived cells, show 
minimal long-term engraftment or cardiac differentiation and instead work principally through paracrine signaling pathways ${ }^{[44]}$.

\subsection{Adipose-derived stem cells}

Adipose-derived stem cells were found in adipose tissue and have recently attracted substantial attention as a source of stem cells with multiple potentials to differentiate into cartilage, vascular and muscle tissues including cardiomyocytes. These cells can be harvested easily from subcutaneous adipose tissue under local anesthesia by a procedure known as lipoaspiration. Adipose-derived stem cells are adult stem cells that morphologically resemble mesenchymal cells from bone marrow, which is why they are sometimes called adiposederived mesenchymal cells. Different approaches for the differentiation of adipose-derived stem cells into cardiomyocytes have been reported, including treatment of permeabilized adipose-derived stem cells by a nuclear and cytoplasmic extract from rat cardiomyocytes $^{[49]}$. Interestingly, these cells were able to differentiate spontaneously when grafted into the myocardium without any preliminary treatment ${ }^{[50]}$. Expression of multiple cardiomyocytespecific markers also was reported including sarcomeric $\alpha$-actinin, desmin and cardiac troponin $\mathrm{I}^{[49]}$. The other distinct characteristics of cardiomyocytes that were observed in differentiating adipose-derived stem cells are appearance of sarcomeric striations, multinucleation and formation of beating cells, that all strongly argue for functional differentiation into cardiac myocytes of the adipose-derived stem cells $^{[49]}$.

\subsection{Embryonic Stem Cells and Induced Pluripotent Stem Cells}

Initial attempts at the differentiation of human embryonic stem cells (hESC) were started as soon as the first hESC cell line was derived in 1998 at the University of Wisconsin. It is now known that hESC are derived from the pluripotent inner cell mass of early blastocyst embryos. They have active telomerase and can rebuild shortening chromosome ends, and therefore, are considered to be immortal. Under selected conditions in cell culture, ESC are able to differentiate into multiple cell types. Early approaches resulting in spontanous differentiation resulted in a very low cardiomyocyte output (5-10\%). Current approaches for inducing cardiomyocyte differentiation in culture routinely use activin A in combination with bone morphogenetic protein 4 (BMP4) $)^{[51]}$. In another protocol, BMP2 (bone morphogenic protein 2), TGF $\beta$ (transforming growth factor) and TNFa (tumor necrosis factor) ${ }^{[52]}$ were used to induce cardiac differentiation of hESC in culture. Others have reported that activation of the receptor for tyrosine-protein kinase, erbB-4 pathway by growth factors, neuregulins-2 and heparin-binding EGF-like growth factor, significantly enhance cardiac differentiation ${ }^{[52]}$. Some micro-RNAs induce cardiomyocyte proliferation, as well as differentiation of hESC and iPSC. MiR-499 (myomiR family) was reported to enhance differentiation of definitive myocardial cells from human cardiac progenitor cells and hESC $^{[53,54]}$.

In our laboratory, we use the approach of combining the formation of embryoid bodies followed by treatment with a new form of MiR-499 that increases cardiomyocyte output up to $70-80 \%$ as determined by the expression of cardiac-specific troponin-T and tropomyosin ${ }^{[55]}$. In addition, we have discovered a new cardiac -inducing RNA (CIR) that also significantly enhances cardiac differentiation from mESC and human iPSC; this RNA does not belong to the micro-RNA family, but rather appears to be part of RNA coding genes ${ }^{[56]}$. In our earlier studies, computer analyses of RNA secondary structures show significant similarities to a previously discovered myofibril-inducing RNA (MIR) described in salamander, that also promotes nonmuscle cells to differentiate into cardiac muscle in salamander hearts as well as mouse and human stem cells ${ }^{[57,58]}$.
One of the problems that has been reported is that the retention rate of ESC in heart grafts is very low and the engrafted ESC do not appear to survive in the heart for prolonged periods ${ }^{[59]}$. The amount of detectable engrafted cells becomes very low after 2-3 weeks transplantation ${ }^{[60,61]}$. From this observation, many researchers have concluded that the majority of benefit for heart regeneration after MI is likely via paracrine effects of the cell ${ }^{[62]}$. This problem potentially may have another consequence; if engrafted cells do not stay at the place of engraftment, but are swept away by blood flow or by some other cellular movement/migratory mechanism and end up residing in other organs, they could contribute to tumor/cancer development. To help resolve this issue, researchers have invented a "pro-survival cocktail", including IGF1 $\left(100 \mathrm{ng} \mathrm{ml}^{-1)}\right.$ and cyclosporine A $(0.2 \mathrm{mM})$, that helps to enhance retention and survival of engrafted cells after transplantation into the recipient heart ${ }^{[61]}$.

Another potential problem with using hESC to generate cardiac tissue is the problem that allogenic cells will require life-long immunosuppression therapy. This problem may be resolved with cardiomyocytes differentiated from a patient's own iPSC that presumably are completely immune autologous. In spite of these potential concerns, there are multiple reports of successful differentiation of grafted iPSC that form into functional cardiomycytes in hearts of different species contributing to heart regeneration after myocardial infarction ${ }^{[62,63]}$. It seems likely that increased success may result from using inbred lines of a given species which have genetically similar allopathic strains with reduced immunogenic reactions to the transplanted cells. Using iPSC derived from the same animal (or same human patient) should eliminate totally the immunocompatability problem in these kinds of procedures.

Other concerns have been expressed relative to those approaches used to induce potentially transplanted pluripotent cells with virus vectors for cell de-differentiation; if such viruses cause disease or cancer, integration into a recipient's genome or transformation of healthy cells into cancer cells would be a major medical problem. This problem now may be able to be resolved by using dedifferentiated iPSC formed with non-viral vectors. Human iPSC are functionally similar to human embryonic stem cells, in that they express the same markers of pluripotency. Molecular mechanisms of cardiomyocyte differentiation remain unknown; thus, approaches used for differentiation are currently rather empirical. Considering the similarities in differentiation properties between hESC and iPSC, their differentiation into cardiomyocytes logically would seem to be able to use similar approaches. Clearly, further experimentation using in vitro and in vivo approaches will be required to determine the best ways to accomplish the induced differentiation of pluripotent stem cells to form into normal functioning cardiac muscle tissue in vivo. Once accomplished, this technology would lead to the regeneration of cardiac muscle in patients who have suffered from heart damage due to heart attacks or other disease processes such that these patients could fully recover and return to pre-heart-attack activity levels again.

\section{Summary}

Numerous studies have been completed on heart development with respect to finding ways to regenerate functional cardiac muscle tissue after myocardial damage has resulted from acute myocardial infarction (AMI) or related cardiac disease processes. Although a variety of approaches have been used to stimulate nonmuscle tissues/cells to differentiate into cardiac lineages in vitro and in vivo with variable levels of success, reliable and reproducible clinical protocols to regenerate new healthy heart muscle tissue to treat human patients after myocardial infarction or other disease processes 
have yet to be achieved. It has been well known that heart disease is the leading cause of death, accounting for over 8,500,000 individuals every year worldwide. Also, every year millions of people have heart attacks (acute myocardial infarctions) and survive. Since human cardiac tissue does not regenerate significantly following injury, many of these survivors' physical activities, quality of life and independence are impaired. The development of new regenerative medical technologies through continued research in replacing damaged cardiac muscle tissue using stem cells and/or growth factors hold great promise for future cures of the many people around the world affected by cardiac disease. Being able to define the mechanism(s) directing and regulating the differentiation of nonmuscle cells (e.g., induced pluripotent stem cells) to form into vigorously and rhythmically contracting cardiac muscle tissue would represent a major breakthrough in modern medicine and biology. Moreover, being able to convert nonmuscle stem cells from a given patient for use in the repair of damaged heart or other tissues in that same patient promises to provide an immunologically compatible cure for heart and other diseases with tremendous medical, humanitarian and economic benefits to our society and to the world.

\section{References}

1. Sparrow, CP, Olszewski, J. Cellular oxidation of low density lipoprotein is caused by thiol production in media containing transition metal ions. J Lipid Res. 1993:34 (7):1219-28.

2. Ross R. Atherosclerosis - An inflammatory disease. N Engl J Med. 1999:340 (2):115-26.

3. Moore KJ, Sheedy FJ, Fisher EA. Macrophages in atherosclerosis: a dynamic balance. Nat Rev Immunol. 2013;13(10):709-21.

4. Boffito M, Sartori S, Ciardelli G. Polymeric scaffolds for cardiac tissue engineering: requirements and fabrication technologies. Polym Int 2014; 63:2-11.

5. Tallawi M, Rosellini E, Barbani N, Cascone MG, Rai R, SaintPierre G, Boccaccini AR. Strategies for the chemical and biological functionalization of scaffolds for cardiac tissue engineering: a review. J R Soc Interface. 2015;12(108):20150254.

6. Wang B, Wang G, To F, Butler JR, Claude A, McLaughlin RM, Williams LN, de Jongh Curry AL, Liao J. Myocardial scaffoldbased cardiac tissue engineering: application of coordinated mechanical and electrical stimulations. Langmuir. 2013;29(35):11109-17.

7. Alrefai MT, Murali D, Paul A, Ridwan KM, Connell JM, ShumTim D. Cardiac tissue engineering and regeneration using cellbased therapy. Stem Cells Cloning. 2015:8:81-101.

8. Davis ME, Motion JP, Narmoneva DA, Takahashi T, Hakuno D, Kamm RD, Zhang S, Lee RT. Injectable self-assembling peptide nanofibers create intramyocardial microenvironments for endothelial cells. Circulation. 2005;111(4):442-50

9. Soonpaa MH, Kim KK, Pajak L, Franklin M, Field LJ. Cardiomyocyte DNA synthesis and binucleation during murine development. Am J Physiol. 1996;271(5 Pt 2):H2183-9.

10. Soonpaa MH, Field LJ. Assessment of cardiomyocyte DNA synthesis in normal and injured adult mouse hearts. Am J Physiol. 1997 ;272(1 Pt 2):H220-6.

11. Bergmann O, Bhardwaj RD, Bernard S, Zdunek S, Barnabé-Heider F, Walsh S, Zupicich J, Alkass K, Buchholz BA, Druid H, Jovinge $\mathrm{S}$, Frisén J. Evidence for cardiomyocyte renewal in humans. Science. 2009;324(5923):98-102.

12. Senyo SE, Steinhauser ML, Pizzimenti CL, Yang VK, Cai L, Wang M, Wu TD, Guerquin-Kern JL, Lechene CP, Lee RT. Mammalian heart renewal by pre-existing cardiomyocytes. Nature. 2013;493(7432):433-6

13. Hsieh PC, Segers VF, Davis ME, MacGillivray C, Gannon J, Molkentin JD, Robbins J, Lee RT. Evidence from a genetic fatemapping study that stem cells refresh adult mammalian cardiomyocytes after injury. Nat Med. 2007;13(8):970-4.

14. Valiente-Alandi I, Albo-Castellanos C, Herrero D, Arza E, GarciaGomez M, Segovia JC, Capecchi M, Bernad A. Cardiac Bmi1(+) cells contribute to myocardial renewal in the murine adult heart. Stem Cell Res Ther. 2015;6:205.
15. Ghazizadeh Z, Vahdat S, Fattahi F, Fonoudi H, Omrani G, Gholampour M, Aghdami N. Isolation and characterization of cardiogenic, stem-like cardiac precursors from heart samples of patients with congenital heart disease. Life Sci. 2015;137:105-15.

16. Wei K, Serpooshan V, Hurtado C, Diez-Cuñado M, Zhao M, Maruyama S, Zhu W, Fajardo G, Noseda M, Nakamura K, Tian X, Liu Q, Wang A, Matsuura Y, Bushway P, Cai W, Savchenko A, Mahmoudi M, Schneider MD, van den Hoff MJ, Butte MJ, Yang PC, Walsh K, Zhou B, Bernstein D, Mercola M, Ruiz-Lozano P. Epicardial FSTL1 reconstitution regenerates the adult mammalian heart. Nature. 2015;525(7570):479-85.

17. Chen J, Huang ZP, Seok HY, Ding J, Kataoka M, Zhang Z, Hu X, Wang G, Lin Z, Wang S, Pu WT, Liao R, Wang DZ. Mir-17-92 cluster is required for and sufficient to induce cardiomyocyte proliferation in postnatal and adult hearts. Circ Res. 2013 ;112(12):1557-66.

18. Pandey R, Ahmed RPH. MicroRNAs inducing proliferation of quiescent adult cardiomyocytes. Cardiovasc Regen Med. 2015;2(1). pii:e519.

19. Liang D, Li J, Wu Y, Zhen L, Li C, Qi M, Wang L, Deng F, Huang J, Fei L, Liu Y, Ma X, Yu Z, Zhang Y, Chen YH. miRNA204 drives cardiomyocyte proliferation via targeting Jarid2. Int J Cardiol. 2015;201:38-48.

20. Pascual-Gil S, Simón-Yarza T, Garbayo E, Prosper F, BlancoPrieto MJ. Tracking the in vivo release of bioactive NRG from PLGA and PEG-PLGA microparticles in infarcted hearts. J Controlled Release. 2015; 220(Pt A): 388-396.

21. Clark AL, Naya FJ. MicroRNAs in the myocyte enhancer factor 2 (MEF2)-regulated Gt12-Dio3 noncoding RNA locus promote cardiomyocyte proliferation by targeting the transcriptional coactivator Cited2. J Biol Chem. 2015;290(38):23162-72.

22. Das S, Halushka MK. Extracellular vesicle microRNA transfer in cardiovascular disease. Cardiovasc Pathol. 2015;24(4):199-206.

23. Kishore R, Khan M. More than tiny sacks: Stem cell exosomes as cell-free modality for cardiac repair. Circ Res. 2016;118(2):33043.

24. Khan M, Nickoloff E, Abramova T, Johnson J, Verma SK, Krishnamurthy P, Mackie AR, Vaughan E, Garikipati VN, Benedict C, Ramirez V, Lambers E, Ito A, Gao E, Misener S, Luongo T, Elrod J, Qin G, Houser SR, Koch WJ, Kishore R. Embryonic stem cell-derived exosomes promote endogenous repair mechanisms and enhance cardiac function following myocardial infarction. Circ Res. 2015;117(1):52-64.

25. Song F, Zhao J, Hua F, Nian L, Zhou XX, Yang Q, Xie YH, Tang HF, Sun JY, Wang SW. Proliferation of rat cardiac stem cells is induced by $2,3,5,4$-tetrahydroxystilbene- $2-O-\beta$-D-glucoside in vitro. Life Sci. 2015;132:68-76.

26. Zhao YY, Sawyer DR, Baliga RR, Opel DJ, Han X, Marchionni MA, Kelly RA. Neuregulins promote survival and growth of cardiac myocytes. Persistence of ErbB2 and ErbB4 expression in neonatal and adult ventricular myocytes. J Biol Chem. 1998;273(17):10261-9.

27. Yutzey KE. Regenerative biology: Neuregulin 1 makes heart muscle. Nature. 2015;520(7548):445-6.

28. D'Uva G, Aharonov A, Lauriola M, Kain D, Yahalom-Ronen Y, Carvalho S, Weisinger K, Bassat E, Rajchman D, Yifa O, Lysenko M, Konfino T, Hegesh J, Brenner O, Neeman M, Yarden Y, Leor J, Sarig R, Harvey RP, Tzahor E. ErbB2 triggers mammalian heart regeneration by promoting cardiomyocyte dedifferentiation and proliferation. Nat Cell Biol. 2015;17(5):627-38.

29. Polizzotti BD, Ganapathy B, Walsh S, Choudhury S, Ammanamanchi N, Bennett DG, dos Remedios CG, Haubner BJ, Penninger JM, Kühn B. Neuregulin stimulation of cardiomyocyte regeneration in mice and human myocardium reveals a therapeutic window. Sci Transl Med. 2015;7(281):281ra45.

30. Formiga FR, Pelacho B, Garbayo E, Imbuluzqueta I, Díaz-Herráez P, Abizanda G, Gavira JJ, Simón-Yarza T, Albiasu E, Tamayo E, Prósper F, Blanco-Prieto MJ. Controlled delivery of fibroblast growth factor-1 and neuregulin-1 from biodegradable microparticles promotes cardiac repair in a rat myocardial infarction model through activation of endogenous regeneration. J Control Release. 2014;173:132-9. 
31. Lin Z, Pu WT. Harnessing Hippo in the heart: Hippo/Yap signaling and applications to heart regeneration and rejuvenation. Stem Cell Res. 2014;13(3 Pt B):571-81.

32. Tian Y, Liu Y, Wang T, Zhou N, Kong J, Chen L, Snitow M, Morley M, Li D, Petrenko N, Zhou S, Lu M, Gao E, Koch WJ, Stewart KM, Morrisey EE. A microRNA-Hippo pathway that promotes cardiomyocyte proliferation and cardiac regeneration in mice. Sci Transl Med. 2015;7(279):279ra38.

33. Waksman R, Baffour R. Bone marrow and bone marrow derived mononuclear stem cells therapy for the chronically ischemic myocardium. Cardiovasc Radiat Med. 2003;4(3):164-8.

34. Nuri MM, Hafeez S. Autologous bone marrow stem cell transplant in acute myocardial infarction.J Pak Med Assoc 2012;62(1):2-6.

35. Strauer BE, Steinhoff G. 10 years of intracoronary and intramyocardial bone marrow stem cell therapy of the heart: from the methodological origin to clinical practice. J Am Coll Cardiol. 2011;58(11):1095-104.

36. Tondreau T, Lagneaux L, Dejeneffe M, Delforge A, Massy M, Mortier C, Bron D. Isolation of BM mesenchymal stem cells by plastic adhesion or negative selection: phenotype, proliferation kinetics and differentiation potential. Cytotherapy 2004. 6(4):372379.

37. Konstantinou D, Lei M, Xia Z, Kanamarlapudi V. Growth factors mediated differentiation of mesenchymal stem cells to cardiac polymicrotissue using hanging drop and bioreactor. Cell Biol Int. 2015;39(4):502-7.

38. Hafez P, Jose S, Chowdhury SR, Ng MH, Ruszymah BH, Abdul Rahman Mohd R. Cardiomyogenic differentiation of human sternal bone marrow mesenchymal stem cells using a combination of basic fibroblast growth factor and hydrocortisone. Cell Biol Int. 2016 ;40(1):55-64.

39. Hatzistergos KE, Quevedo H, Oskouei BN, Hu Q, Feigenbaum GS, Margitich IS, Mazhari R, Boyle AJ, Zambrano JP, Rodriguez JE, Dulce R, Pattany PM, Valdes D, Revilla C, Heldman AW, McNiece I, Hare JM. Bone marrow mesenchymal stem cells stimulate cardiac stem cell proliferation and differentiation. Circ Res. 2010;107(7):913-22.

40. Iso Y, Spees JL, Serrano C, Bakondi B, Pochampally R, Song YH, Sobel BE, Delafontaine P, Prockop DJ. Multipotent human stromal cells improve cardiac function after myocardial infarction in mice without long-term engraftment. Biochem Biophys Res Commun. 2007;354(3):700-6.

41. Leiker M, Suzuki G, Iyer VS, Canty JM Jr, Lee T. Assessment of a nuclear affinity labeling method for tracking implanted mesenchymal stem cells. Cell Transplant. 2008;17(8):911-22.

42. Murry CE, Palpant NJ, MacLellan WR. Cardiopoietry in motion: primed mesenchymal stem cells for ischemic cardiomyopathy. J Am Coll Cardiol. 2013;61(23):2339-40.

43. Gallina C, Turinetto V, Giachino C. A new paradigm in cardiac regeneration: The mesenchymal stem cell secretome. Stem Cells Int. 2015;2015:765846.

44. Chimenti I, Smith RR, Li TS, Gerstenblith G, Messina E, Giacomello A, Marbán E. Relative roles of direct regeneration versus paracrine effects of human cardiosphere-derived cells transplanted into infarcted mice. Circ Res. 2010;106(5):971-80.

45. Zhang M, Liu D, Li S, Chang L, Zhang Y, Liu R, Sun F, Duan W, Du W, Wu Y, Zhao T, Xu C, Lu Y. Bone marrow mesenchymal stem cell transplantation retards the natural senescence of rat hearts. Stem Cells Transl Med. 2015;4(5):494-502.

46. Mansilla E, Roque G, Sosa YE, Tarditti A, Goya RG. A rat treated with mesenchymal stem cells lives to 44 months of age. Rejuvenation Res. 2016;19(4):318-21.

47. Messina E, De Angelis L, Frati G, Morrone S, Chimenti S, Fiordaliso F, Salio M, Battaglia M, Latronico MV, Coletta M, Vivarelli E, Frati L, Cossu G, Giacomello A. Isolation and expansion of adult cardiac stem cells from human and murine heart. Circ Res. 2004;95(9):911-21.

48. Smith RR, Barile L, Cho HC, Leppo MK, Hare JM, Messina E, Giacomello A, Abraham MR, Marbán E. Regenerative potential of cardiosphere-derived cells expanded from percutaneous endomyocardial biopsy specimens. Circulation. 2007;115(7):896908 .

49. Gaustad KG, Boquest AC, Anderson BE, Gerdes AM, Collas P. Differentiation of human adipose tissue stem cells using extracts of rat cardiomyocytes. Biochem Biophys Res Commun. 2004;314(2):420-7.

50. Strem BM1, Zhu M, Alfonso Z, Daniels EJ, Schreiber R, Beygui R, MacLellan WR, Hedrick MH, Fraser JK. Expression of cardiomyocytic markers on adipose tissue-derived cells in a murine model of acute myocardial injury. Cytotherapy. 2005;7(3):282-91.

51. Chong JJ, Yang X, Don CW, Minami E, Liu YW, Weyers JJ, Mahoney WM, Van Biber B, Cook SM, Palpant NJ, Gantz JA, Fugate JA, Muskheli V, Gough GM, Vogel KW, Astley CA, Hotchkiss CE, Baldessari A, Pabon L, Reinecke H, Gill EA, Nelson V, Kiem HP, Laflamme MA, Murry CE. Human embryonic-stem-cell-derived cardiomyocytes regenerate nonhuman primate hearts. Nature. 2014;510(7504):273-7

52. Hamidi S, Letourneur D, Aid-Launais R, Di Stefano A, Vainchenker W, Norol F, Le Visage C. Fucoidan promotes early step of cardiac differentiation from human embryonic stem cells and long-term maintenance of beating areas. Tissue Eng Part A. 2014;20(7-8):1285-94.

53. Sluijter JP, van Mil A, van Vliet P, Metz CH, Liu J, Doevendans PA, Goumans MJ. MicroRNA-1 and -499 regulate differentiation and proliferation in human-derived cardiomyocyte progenitor cells. Arterioscler Thromb Vasc Biol. 2010;30(4):859-68.

54. Wilson KD, Hu S, Venkatasubrahmanyam S, Fu JD, Sun N, Abilez OJ, Baugh JJ, Jia F, Ghosh Z, Li RA, Butte AJ, Wu JC. Dynamic microRNA expression programs during cardiac differentiation of human embryonic stem cells: role for miR-499. Circ Cardiovasc Genet. 2010;3(5):426-35.

55. Kochegarov A, Moses-Arms A, Hanna M, Lemanski LF. Micro RNA-499c induces the differentiation of stem cells into cardiomyocytes. International Archives of Medicine. 2015; 8(58).

56. Kochegarov A, Moses-Arms A, Lemanski LF. A fetal human heart cardiac-inducing RNA (CIR) promotes the differentiation of stem cells into cardiomyocytes. In Vitro Cell Dev Biol Anim. 2015;51(7):739-48.

57. Moses-Arms A, Kochegarov A, Arms J, Burlbaw S, Lian W, Meyer J, Lemanski LF. Identification of a human mitochondrial RNA that promotes tropomyosin synthesis and myocardial differentiation. In Vitro Cell Dev Biol Anim. 2015;51(3):273-80.

58. Zhang C, Jia P, Huang X, Sferrazza GF, Athauda G, Achary MP, Wang J, Lemanski SL, Dube DK, Lemanski LF. Myofibrilinducing RNA (MIR) is essential for tropomyosin expression and myofibrillogenesis in axolotl hearts. J Biomed Sci. 2009;16:81.

59. Ye J, Gaur M, Zhang Y, Sievers RE, Woods BJ, Aurigui J, Bernstein HS, Yeghiazarians Y. Treatment with hESC-derived myocardial precursors improves cardiac function after a myocardial infarction. PLoS One. 2015;10(7):e0131123.

60. van Laake LW, Passier R, den Ouden K, Schreurs C, Monshouwer-Kloots J, Ward-van Oostwaard D, van Echteld CJ, Doevendans PA, Mummery CL. Improvement of mouse cardiac function by hESC-derived cardiomyocytes correlates with vascularity but not graft size. Stem Cell Res. 2009;3(2-3):106-12.

61. Yeghiazarians Y, Gaur M, Zhang Y, Sievers RE, Ritner C, Prasad M, Boyle A, Bernstein HS. Myocardial improvement with human embryonic stem cell-derived cardiomyocytes enriched by p38MAPK inhibition. Cytotherapy. 2012;14(2):223-31.

62. Ye L, Chang YH, Xiong Q, Zhang P, Zhang L, Somasundaram P, Lepley M, Swingen C, Su L, Wendel JS, Guo J, Jang A, Rosenbush D, Greder L, Dutton JR, Zhang J, Kamp TJ, Kaufman DS, Ge Y, Zhang J. Cardiac repair in a porcine model of acute myocardial infarction with human induced pluripotent stem cellderived cardiovascular cells. Cell Stem Cell. 2014;15(6):750-61.

63. Wendel JS, Ye L, Tao R, Zhang J, Zhang J, Kamp TJ, Tranquillo RT. Functional effects of a tissue-engineered cardiac patch from human induced pluripotent stem cell-derived cardiomyocytes in a rat infarct model. Stem Cells Transl Med. 2015;4(11):1324-32. 


$\begin{array}{ll}\text { Abbreviations } & \\ \text { AMI: } & \text { Acute myocardial infarction } \\ \text { BM-MNC: } & \text { Bone marrow mononuclear cells } \\ \text { BMP2: } & \text { Bone morphogenic protein 2 } \\ \text { BMP4: } & \text { Bone morphogenetic protein } 4 \\ \text { CDC: } & \text { Cardiosphere-derived cells } \\ \text { CSC: } & \text { Cardiac stem cells } \\ \text { EGF: } & \text { Epidermal growth factor } \\ \text { EPCs: } & \text { Endothelial progenitor cells } \\ \text { ESC: } & \text { Embryonic stem cells } \\ \text { FGF1: } & \text { Acidic fibroblast growth factor } \\ \text { FSTL1: } & \text { Follistatin-like protein 1 } \\ \text { hESC: } & \text { Human embryonic stem cells } \\ \text { IGF1: } & \text { Inhibiting growth factor } \\ \text { iPSC: } & \text { Induced pluripotent stem cells } \\ \text { LDL: } & \text { Low-density lipoprotein } \\ \text { mESC: } & \text { Mouse embryonic stem cells } \\ \text { MI: } & \text { Myocardial infarction } \\ \text { MSC: } & \text { Mesenchymal stem cells } \\ \text { NRG1: } & \text { Neuregulin-1 } \\ \text { TGF } \beta: & \text { Transforming growth factor } \\ \text { TNF }: & \text { Tumor necrosis factor } \\ \end{array}$

\section{Potential Conflicts of Interests}

None

\section{Acknowledgments}

We are grateful to Ms Mallory Dennie and Ms Sharon L Lemanski for excellent secretarial support during the preparation of the manuscript.

The current affiliation for Dr. Kochegarov is: Dr. Andrei Kochegarov, UCLA Peds-Neonatology, Box 951752, A-3-375, Los Angeles, California, 90095-1752, USA. E-mail: aKochegarov@ mednet.ucla.edu

\section{Grants}

National Institutes of Health, Bethesda, Maryland 20892, USA; National Science Foundation, Arlington, Virginia 22230, USA; American Heart Association, Dallas, Texas 75231, USA; Chancellor's Research Initiative, Texas A\&M University System, College Station, TX 77840, USA awarded to Dr. Lemanski.

\section{Corresponding Author}

Lemanski, Larry F, Department of Biological and Environmental Sciences, Texas A\&M University-Commerce, PO Box 3011, Commerce, Texas, 75429, USA; E-mail: Larry.Lemanski@tamuc.edu; 